\title{
Influence of Land Use Intensity and Management on Arbuscular Mycorrhizal Fungi-Avocado Symbiosis
}

\author{
P. G. Soti ${ }^{1}$, Bulent Toprak ${ }^{2}$, Nina De La Rosa ${ }^{3} \&$ Krish Jayachandran ${ }^{3}$ \\ ${ }^{1}$ Biology Department, University of Texas Rio Grande Valley, Texas, United States \\ ${ }^{2}$ Faculty of Forestry, İzmir Kâtip Çelebi University, İzmir, Turkey \\ ${ }^{3}$ Department of Earth and Enviornment, Florida International University, Florida, United States \\ Correspondence: Pushpa Soti, Biology Department, University of Texas Rio Grande Valley, Edinburg, TX 78539 , \\ United States. Tel: 1-956-665-3131.E-mail: pushpa.soti@utrgv.edu
}

Received: November 24, 2020

Accepted: January 5, 2021

Online Published: February 15, 2021

doi:10.5539/jas.v13n3p10

URL: https://doi.org/10.5539/jas.v13n3p10

This research was funded by the United States Department of Agriculture NIFA Hispanic-Serving Institutions Higher Education Grants Program (2015-38422-24075).

\begin{abstract}
This study was done to assess the effect of soil disturbance on arbuscular mycorrhizal fungi spore abundance and root colonization in avocado (Persea americana Mill.). Rhizosphere soil and root samples of avocado were collected from different farms in south Florida and analyzed for degree of mycorrhizal colonization in roots, spore density and diversity in soil along with soil characteristics. There was significant difference in the soil characteristics among the different farms. Similarly, there was a significant difference in the degree of mycorrhizal colonization in the roots and the arbuscular mycorrhizal fungi spore morphotypes among different land use and management practices. However, there was no significant difference in the total number of arbuscular mycorrhizal fungi spores among these sites. There was no correlation between the number of arbuscular mycorrhizal fungi spores and soil characteristics. However, arbuscular mycorrhizal fungi colonization in roots were strongly influenced by soil characteristics such as soil moisture, carbon, nitrogen, and organic matter. Further research is necessary to identify these AMF species and determine the role of in avocado growth tolerance to anthropogenic disturbance in highly disturbed urban soils.
\end{abstract}

Keywords: mycorrhizal fungi, soil management, soil use, organic farming, conventional farming

\section{Introduction}

After citrus, avocado (Persea americana Mill.) industry is the largest fruit industry in Florida. The avocado industry is an important part of the Florida agriculture economy and consists of about 7,400 acres of land area mainly in the Miami-Dade County (De Oleo et al., 2010). Avocado trees do not tolerate flooding and grow well in the well-drained sandy and limestone soils of south Florida. Tropical climate in south Florida provides an ideal climate for avocado and it is highly localized in the south-eastern Miami Dade County (Ploetz, 2007).

Avocado trees are shallow rooted with dense proliferation of fine roots close to the surface (Salazar-Garcia \& Cortés-Flores, 1986). These roots are protected by the trees own natural much. Using mulch in avocadoes is reported to supress insect pests (Hoddle, Robinson, Brownbridge, \& Ley, 2002), suppress white root rot (Bonilla et al., 2015), and increase root growth and fruit yield (Moore-Gordon, Cowan, \& Wolstenholme, 1997). Past research has shown that avocado roots are colonized with arbuscular mycorrhizal fungi (AMF) (Menge, Davis, Johnson, \& Zentmyer, 1978; Haas \& Menge, 1990; Toprak, Soti, Jovel, Alverado, \& Jayachandran, 2017; Viera et al., 2017) and AMF improve growth of avocado seedlings especially by increasing the availability of phosphorus (Menge et al., 1978; Menge, Larue, Labanauskas, \& Johnson, 1980). Thus, soil disturbance in the root zone can not only reduce the feeder roots but can also influence the avocado-AMF symbiosis through the repeated damage to AMF hyphal matts (Kabir, 2005; Urcelay et al., 2009). Furthermore, changes in the soil environmental conditions such as soil compaction, nutrients, soil $\mathrm{pH}$, light, and temperature resulting from soil disturbance can influence the mycorrhizal fungi colonization (Dumbrell et al., 2011; That \& Sijam, 2012; Verbruggen, van der Heijden, Rillig, \& Kiers, 2013; Soti, Jayachandran, Koptur, \& Volin, 2015). 
Studies investigating the influence of land use on AMF have reported that AMF are resilient to disturbance (Dai, Bainard, Hamel, Gan, \& Lynch, 2013; Jansa, Erb, Oberholzer, Šmilauer, \& Egli, 2014). Conversely, there are some studies that report land use practices causing negative impact on the AMF community (Douds \& Millner, 1999; Manoharan, Rosenstock, Williams, \& Hedlund, 2017; González-Cortés et al., 2012). It has also been reported that the influence of soil properties on AMF communities is site specific (Mangan, Eom, Adler, Yavitt, \& Herre, 2004; Pereira, da Silva, de Almeida Ferreira, Goto, \& Maia, 2014). For example, (Carrillo-Saucedo, Gavito, \& Siddique, 2018) reported that diversity, evenness, and richness indices of AMF was lower in climax communities such as forests compared to continuously disturbed agricultural fields. However, Bainard et al. (2015) in their study in tropical dry forest ecosystem found that AMF fungal spore communities were resistant to land-use change and management.

While there are studies reporting AMF benefits on avocado seedlings, there is little information on the influence of anthropogenic soil disturbance on the AMF-avocado symbiosis in established trees. We conducted a preliminary survey to understand the impact of disturbance and organic vs conventional farm management practices on the AMF root colonization in avocado trees.

\section{Materials and Methods}

\subsection{Study Sites}

To include different land management practices, we selected two pairs of farms, organic and conventional, in both urban and peri-urban sites in Miami-Dade County Florida (Table 1). These agricultural growing areas of Miami-Dade County, situated between burgeoning urban and suburban metropolis of Miami, produce a wide variety of traditional and tropical vegetables, tropical fruits, and ornamental nursery and greenhouse products, along with smaller quantities of seed crops (Degner, Stevens, Mulkey, \& Hodges, 2000).

Table 1. Information on different sampling sites, type, level of disturbance and location

\begin{tabular}{|c|c|c|}
\hline Site & Farm management & Site description \\
\hline Peri-urban (PRO) & Organic & $\begin{array}{l}\text { Possum Trot is non-certified organic farm located in the Redlands Agriculture Area of Miami } \\
\text { Dade County. The land has been under organic management for the past } 25 \text { years. The } \\
\text { avocado trees in the farm have an average of } 25-35 \text { years and very low anthropogenic } \\
\text { disturbance. Avocado leaf mulch not disturbed. }\end{array}$ \\
\hline Peri-urban (PRC) & Conventional & $\begin{array}{l}\text { This farm is also located in the Redlands Agricultural Area of Miami Dade county. This site } \\
\text { has been managed conventionally (applications of pesticides). The avocado trees here are } \\
\text { more than } 10 \text { years old and low anthropogenic disturbance. Avocado leaf mulch not disturbed. }\end{array}$ \\
\hline Urban (URC) & Conventional & $\begin{array}{l}\text { The site is located at the corner of } 147^{\text {th }} \text { and } 184^{\text {th }} \text { street in South West Miami Dade County. } \\
\text { While historically this site had been occupied by a conventional avocado farm, recent urban } \\
\text { expansion transformed it into an urban area surrounded by single family homes and shopping } \\
\text { plaza. The age of avocado trees here is unknown and very high anthropogenic disturbance: } \\
\text { soil disturbance, and compaction due to high human traffic). Natural avocado leaf mulch } \\
\text { disturbed and mostly removed by human traffic. }\end{array}$ \\
\hline Urban (URO) & Organic & $\begin{array}{l}\text { Located at the Florida International University organic garden. The fruit forest has a wide } \\
\text { variety of tropical fruit trees. The avocado trees here are more than } 10 \text { years old and very high } \\
\text { anthropogenic disturbance: soil disturbance and compaction due to high human traffic). } \\
\text { Natural avocado leaf mulch disturbed and mostly removed by human traffic. }\end{array}$ \\
\hline
\end{tabular}

\subsection{Soil and Root Sample Collection}

Six fully grown trees were selected in each of the four sites for sample collection, $n=24$. Rhizosphere soil and root fragments of avocado plants were collected from the study sites during the summer of 2013. Three soil cores (depth between 0 and $12 \mathrm{~cm}$ ) were collected around each selected tree in the four sites and mixed to prepare a composite soil sample. A portion of the soil sample was dried and stored in airtight containers to analyze the physical and chemical properties and the remaining portion was stored in a $4{ }^{\circ} \mathrm{C}$ refrigerator until biological analysis.

Soil samples were analyzed for moisture content by gravimetric method (Reynolds, 1970) and particle size distribution was analyzed using a hydrometer. Soil $\mathrm{pH}$ was measured using a glass probe (1:2 soil DI water solution). Total carbon and nitrogen in soil was measured using a TruSpec Carbon/Nitrogen Analyzer (Leco Corporation, St. Joseph, MI, USA). Total organic matter was measured based on the standard loss on ignition 
method $\left(500^{\circ} \mathrm{C}, 5\right.$ hours, (Storer, 1984)). For total P measurement, soil samples $(0.25 \mathrm{~g}$, finely ground) were ashed $\left(500{ }^{\circ} \mathrm{C}\right)$, digested in $2 \mathrm{ml} \mathrm{HCl}(6 \mathrm{~N})$ and $10 \mathrm{ml} \mathrm{HNO}_{3}$, and analyzed with an UV spectrophotometer (Shimadzu Scientific Instruments, Columbia, MD, USA) following the USEPA chemical analysis method (USEPA, 1983).

\subsection{Arbuscular Mycorrhizal Fungal Spores Extraction and Identification}

Arbuscular mycorrhizal fungal (AMF) spores were extracted and separated from the soil using wet sieving and decanting followed by sucrose density gradient technique (Gerdemann \& Nicolson, 1963). Fifty-gram dry equivalent weight soil from each site was placed in a $250 \mathrm{ml}$ beaker. One hundred $\mathrm{ml}$ DI water was added to the soil and mixed vigorously to separate the spores from soil aggregates. The slurry mixture was washed through a series of sieves $(2 \mathrm{~mm}, 100 \mu \mathrm{m}$ and $32 \mu \mathrm{m})$. This process was repeated several times until the water flowing through the sieves was clear. The sievate retained on each sieve was washed into a $50 \mathrm{ml}$ centrifuge tube. The tubes containing sievate were balanced and centrifuged at $300 \mathrm{rpm}$ for three minutes to remove floating organic debris. After centrifugation, the supernatant was discarded. The pellet in the bottom was re-suspended in a 50\% sucrose solution and centrifuged at $2000 \mathrm{rpm}$ for one minute to separate the AMF spores from denser sucrose solution. Immediately after centrifugation, AMF spores in the sucrose supernatant were rinsed in a fine $32 \mu \mathrm{m}$ sieve to rinse off sucrose. The AMF spores were collected on a Whatman number 42 filter paper by vacuum filtration. The filter paper containing AMF spores was placed under a stereomicroscope at $100 \times$ and $400 \times$ magnification for observation. The AMF spores were separated based on color, size, type, and morphology of the subtending hypha attached at the spore wall. The AMF spores were mounted on microscopic slides for taxonomic identification based on the spore morphology and wall characteristics, using the descriptions by the International Culture Collection of Arbuscular and Vesicular-Arbuscular Mycorrhizal Fungi (http:// invam.caf.wvu.edu). Since the spores were field samples, some small and irregular shaped spores could not be identified at species level, they were grouped as unidentified.

\subsection{Degree of Mycorrhizal Colonization in Roots}

Twenty-five $1.5 \mathrm{~cm}$ root fragments were collected from the randomly selected four plants in each site, and the colonization of AMF was quantified by staining the roots with Trypan blue (McGonigle et al., 1990). Roots were cleared in $15 \% \mathrm{KOH}$ at $70{ }^{\circ} \mathrm{C}$ for 4 hours, rinsed twice with tap water, bleached with ammoniated $\mathrm{H}_{2} \mathrm{O}_{2}$, and acidified with $1 \mathrm{~N} \mathrm{HCl}$. Root staining was done using Trypan blue in acidified glycerol at $80{ }^{\circ} \mathrm{C}$ for 20 minutes. The stained roots were then examined with a dissecting microscope at 30-60× magnification for the degree of mycorrhizal colonization; the portions that showed the presence of mycorrhizal fungi were mounted on slides and examined at 100-400× magnification to further analyze various mycorrhizal structures such as vesicles, arbuscules and hyphe structure. Percentage of mycorrhizal colonization in roots was estimated by:

$$
\% \text { Colonization }=\frac{\text { Total number of AMF root segments }}{\text { Total number of root segments observed }} \times 100
$$

\subsection{Statistical Analysis}

Analysis of variance was done to determine the difference between the different soil characteristics, spore density and degree of mycorrhizal colonization in the roots of avocado among the different sites. Data was tested for normality, and when it failed to pass the normality assumption it was subjected to log transformation (soil moisture, Carbon \%, and AMF\% in roots). Two-way ANOVA was done to analyze the relationship between the two factors site and farm management and AMF root colonization. Means were separated by Fisher LSD and differences were considered significant at a $\mathrm{P}$ value of $<0.05$. Relationship between root mycorrhizal colonization and rhizosphere spore density and soil parameters was evaluated using Pearson correlation analysis. All the data was analyzed using JMP Pro 13 software.

\section{Results}

In this study, we analyzed the farm soil status and mycorrhizal spore density and diversity in avocado growing in different land use types in south Florida. There was a significant difference in the soil status among the different farms (Table 2). Soil $\mathrm{pH}$ in the study sites was slightly alkaline with no significant difference among the farms. However, there was a significant difference in the soil moisture among the different sites $(P<0.001)$. The farms in peri-urban sites had significantly higher moisture compared to the urban site, and highest soil moisture was found in the conventional farm at the peri-urban site. Similarly, for total $\mathrm{N} \%$, conventional farm at the urban site had the lowest amount and there was no significant difference among the other farms $(P=0.001)$. Total $\mathrm{C} \%$ was significantly higher in both the farms at the peri-urban site compared to the urban sites $(P<0.001)$. Soil organic matter \% was also highest in the organic farm at the peri-urban site and lowest at the organic farm in the urban site $(P=0.001)$. 
Table 2. Mean with standard error (SE) in parenthesis of soil characteristics and AMF in the study sites

\begin{tabular}{lllllllll}
\hline Site & $\mathrm{pH}$ & Moisture \% & Total N \% & Total C\% & OM\% & No of Spores & Spore Morphotypes & AMF \% in roots \\
\hline PRO & $7.83(0.06)$ & $14.6(1)$ & $0.54(0.07)$ & $11.98(1.09)$ & $19.95(1.12)$ & $281.83(8.90)$ & $9(0.86)$ & $78(1.74)$ \\
PRC & $7.63(0.15)$ & $19.49(1.96)$ & $0.57(0.08)$ & $9.33(0.93)$ & $15.42(1.35)$ & $272.67(9.81)$ & $7(0.37)$ & $77.16(2.55)$ \\
URO & $7.47(0.05)$ & $4.04(0.44)$ & $0.38(0.08)$ & $3.56(0.59)$ & $11.97(1.01)$ & $275(18)$ & $6.5(0.22)$ & $50.33(2.10)$ \\
URC & $7.68(0.02)$ & $5.4(0.56)$ & $0.15(0.02)$ & $3.62(0.38)$ & $13.73(1.16)$ & $278(10.45)$ & $5.1(0.47)$ & $48(3.11)$ \\
\hline
\end{tabular}

Note. PRO: peri-urban organic; PRC: peri-urban conventional; URO: urban organic; and URC: urban conventional.

The rhizosphere soil sample from different locations harbored different spore types. There was no significant difference in the AMF spore numbers among the different sites (Table 2), however there was a difference in the AMF spore diversity in these sites. We found a total of 15 different AMF morphospecies in the four different study sites. Of the 15 morphospecies, spores of Glomeraceae species were found in all sites in high abundance. Spores of Aculospora spp. and Scutellospora spp. were found in the two peri-urban sites but not found in both the urban sites.

The roots of avocado from all the sampling locations showed signs of high degree of mycorrhizal colonization indicating avocado is highly mycorrhizal (Table 2). The degree of mycorrhizal colonization in the roots ranged from $40 \%$ to $77 \%$ with higher degree of colonization in the peri-urban sites and lower in the urban sites. While the AMF colonization in roots was not significantly different in the organic or conventional farm plants $(P=0.105)$, it was significantly higher in the peri-urban farms with low soil disturbance than the urban farms with high soil disturbance $(P<0.001)$. In addition, the effect of site on root AMF colonization was significant $(P<0.001)$. However, farm management and the interaction of farm management and site had no significant impact on root AMF colonization.

Correlation analysis indicated no significant relationship between the total number of AMF spores and soil characteristics. However, there was a strong correlation between the soil variables and AMF root colonization and the number of spore morphotypes (Table 3). Soil moisture, $\mathrm{pH}$, and $\mathrm{C} \%$ had a significant correlation with the AMF spore morphotypes ( $p<0.001$ and 0.0046 respectively).

Table 3. Correlations with correlation probability in parenthesis between soil variables and mycorrhizal spore density in soil and root colonization by AMF

\begin{tabular}{lllllll}
\hline & $\mathrm{pH}$ & Moisture & Nitrogen\% & Carbon\% & Organic Matter \% & Number of spores \\
\hline Number of spores & $-0.187(0.38)$ & $-0.544(0.65)$ & $0.141(0.50)$ & $0.085(0.32)$ & $0.057(0.79)$ & \\
AMF \% in roots & $0.315(0.31)$ & $0.810(<0.0001)$ & $0.624(0.001)$ & $0.821(0.0001)$ & $0.424(0.039)$ & $0.117(0.52)$ \\
Spore morphotypes & $0.258(0.22)$ & $0.385(0.06)$ & $0.472(0.019)$ & $0.468(0.021)$ & $0.50(0.012)$ & $-0.018(0.93)$ \\
\hline
\end{tabular}

\section{Discussion}

This study presents the results of a preliminary study of disturbance in avocado AMF symbiosis in South Florida farms. Our results show that anthropogenic soil disturbance did not have an influence on the avocado rhizosphere AMF spore abundance. However, the AMF root colonization and spore morphotypes were influenced by anthropogenic soil disturbance which potentially resulted in different soil edaphic conditions. These results are similar to previous studies that found a negative impact of land use intensity on the AMF diversity (Oehl et al., 2003, 2010; Schnoor, Lekberg, Rosendahl, \& Olsson, 2011; Xiang et al., 2014). Major disturbance in our site was mechanical disturbance, leading to the disruption of hyphal network. While we did not identify the AMF spore species using molecular techniques, microscopic analysis of the spores showed the higher presence Glomeraceae species spores. These results are in line with previous studies (van der Heyde, Ohsowski, Abbott, \& Hart, 2017; De León et al., 2018) demonstrating that species in the Glomeraceae were most tolerant to mechanical disturbance. Traits such as high growth rate (Hart \& Reader, 2005), high rate of hyphal turnover (Staddon, Ramsey, Ostle, Ineson, \& Fitter, 2003), and reproduction from both spores and hyphal fragments (Ohel et al., 2009), could potentially result in higher tolerance to disturbance in some AMF species.

High degree of AMF colonization was found in the peri- urban sites while urban site plants had the lower level of mycorrhizal colonization in roots, regardless of the farm management practices. Lower degree of AMF colonization in urban trees roots has been reported in previous studies (Bainard \& Klironomos, 2011). Soil variables such as soil moisture were strongly associated with the root AMF colonization. Avocado plants are 
shallow rooted with most of the fine roots, which absorb water and nutrients, are in the greatest abundance at or near the surface (Coit, 1940). Both the peri-urban sites had the natural mulch which was important in protecting the roots and maintaining higher soil moisture and soil organic matter. Our results indicate that mulch cover not only maintained high soil moisture and organic matter but also potentially increased the AMF colonization in the roots. In addition, both the urban sites were highly disturbed with increased human activities around the trees. Intense anthropogenic activities such constant soil disturbance could lead to the disturbance in the AMF hyphal matts as reported previously (Urcelay et al., 2009).

Overall, while the total number of spores did not vary among the different farms there was significant difference in the AMF colonization in avocado roots and AMF spore morphospecies. The less disturbed peri-urban sites had significantly higher soil organic matter also had higher soil moisture. The natural much, which help to protect the roots from diseases and reduce evaporative water loss in avocadoes, was not existent in the peri-urban highly disturbed sites. Our results show that anthropogenic disturbance removing the natural avocado leaf mulch not only influence the root growth but also the avocado-AMF symbiosis. Further detailed analysis is necessary to determine the role of leaf mulch on promoting the AMF-avocado symbiosis. Also, if we are to use AMF in avocado for seedling establishment and yield increase in mature trees, proper identification the AMF species associated with avocado under field conditions is necessary.

\section{Acknowledgements}

We thank the owners of the avocado farms for allowing us to collect samples from their farms. We also thank the graduate students in the Agroecology Lab at Florida International University for their help in processing the samples. This research was possible by the funding support of the United States Department of Agriculture NIFA Hispanic-Serving Institutions Higher Education Grants Program (2015-38422-24075).

\section{References}

Bainard, L. D., Dai, M., Gomez, E. F., Torres-Arias, Y., Bainard, J. D., Sheng, M., ... Hamel, C. (2015). Arbuscular mycorrhizal fungal communities are influenced by agricultural land use and not soil type among the Chernozem great groups of the Canadian Prairies. Plant and Soil, 387(1-2), 351-362. https://doi.org/ 10.1007/s11104-014-2288-1

Bainard, L. D., Klironomos, J. N., \& Gordon, A. M. (2011). The mycorrhizal status and colonization of 26 tree species growing in urban and rural environments. Mycorrhiza, 21(2), 91-96. https://oi.org/10.1007/ s00572-010-0314-6

Bonilla, N., Vida, C., Martínez-Alonso, M., Landa, B. B., Gaju, N., Cazorla, F. M., \& De Vicente, A. (2015). Organic amendments to avocado crops induce suppressiveness and influence the composition and activity of soil microbial communities. Applied and Environmental Microbiology, 81(10), 3405-3418. https://doi.org/10.1128/AEM.03787-14

Carrillo-Saucedo, S. M., Gavito, M. E., \& Siddique, I. (2018). Arbuscular mycorrhizal fungal spore communities of a tropical dry forest ecosystem show resilience to land-use change. Fungal Ecology, 32, 29-39. https://doi.org/10.1016/j.funeco.2017.11.006

Dai, M., Bainard, L. D., Hamel, C., Gan, Y., \& Lynch, D. (2013). Impact of land use on arbuscular mycorrhizal fungal communities in rural Canada. Applied and Environmental Microbiology, 79(21), 6719-6729. https://doi.org/10.1128/AEM.01333-13

de León, D. G., Neuenkamp, L., Moora, M., Öpik, M., Davison, J., Peña-Venegas, C. P., ... Zobel, M. (2018). Arbuscular mycorrhizal fungal communities in tropical rain forest are resilient to slash-and-burn agriculture. Journal of Tropical Ecology, 34(3), 186. https://doi.org/10.1017/S0266467418000184

De Oleo, B., Evans, E. A., \& Crane, J. H. (2010). Establishment Cost of Avocados in South Florida. Retrieved from https://edis.ifas.ufl.edu/fe956

Degner, R. L., Stevens, T., Mulkey, D., \& Hodges, A. (2000). Economic impact of agriculture and agribusiness in Miami-Dade County, Florida (Industry Report, 1). Florida Agr. Mktg. Res. Ctr.

Douds Jr, D. D., \& Millner, P. D. (1999). Biodiversity of arbuscular mycorrhizal fungi in agroecosystems. Agriculture, Ecosystems \& Environment, 74(1-3), 77-93. https://doi.org/10.1016/S0167-8809(99)00031-6

Dumbrell, A. J., Ashton, P. D., Aziz, N., Feng, G., Nelson, M., Dytham, C., ... Helgason, T. (2011). Distinct seasonal assemblages of arbuscular mycorrhizal fungi revealed by massively parallel pyrosequencing. New Phytologist, 190(3), 794-804. https://doi.org/10.1111/j.1469-8137.2010.03636.x 
Gerdemann, J. W., \& Nicolson, T. H. (1963). Spores of mycorrhizal Endogone species extracted from soil by wet sieving and decanting. Transactions of the British Mycological Society, 46(2), 235-244. https://doi.org/ 10.1016/S0007-1536(63)80079-0

González-Cortés, J. C., Vega-Fraga, M., Varela-Fregoso, L., Martínez-Trujillo, M., Carreón-Abud, Y., \& Gavito, M. E. (2012). Arbuscular mycorrhizal fungal (AMF) communities and land use change: the conversion of temperate forests to avocado plantations and maize fields in central Mexico. Fungal Ecology, 5(1), 16-23. https://doi.org/10.1016/j.funeco.2011.09.002

Haas, J. H., \& Menge, J. A. (1990). VA-mycorrhizal fungi and soil characteristics in avocado (Persea americana Mill.) orchard soils. Plant and Soil, 127(2), 207-212. https://doi.org/10.1007/BF00014427

Hart, M. M., \& Reader, R. J. (2005). The role of the external mycelium in early colonization for three arbuscular mycorrhizal fungal species with different colonization strategies. Pedobiologia, 49(3), $269-279$. https://doi.org/10.1016/j.pedobi.2004.12.001

Hoddle, M. S., Robinson, L., Brownbridge, M., \& Ley, P. D. (2002). Assessing organic mulches for avocado thrips control in California avocado orchards (pp. 129-133). California Conference on Biological Control III, University of California at Davis, USA, August, 15-16, 2002, Center for Biological Control, College of Natural Resources, University of California, USA.

Jansa, J., Erb, A., Oberholzer, H. R., Šmilauer, P., \& Egli, S. (2014). Soil and geography are more important determinants of indigenous arbuscular mycorrhizal communities than management practices in Swiss agricultural soils. Molecular Ecology, 23(8), 2118-2135. https://doi.org/10.1111/mec.12706

Kabir, Z. (2005). Tillage or no-tillage: impact on mycorrhizae. Canadian Journal of Plant Science, 85(1), 23-29. https://doi.org/10.4141/P03-160

Mangan, S. A., Eom, A. H., Adler, G. H., Yavitt, J. B., \& Herre, E. A. (2004). Diversity of arbuscular mycorrhizal fungi across a fragmented forest in Panama: Insular spore communities differ from mainland communities. Oecologia, 141(4), 687-700. https://doi.org/10.1007/s00442-004-1684-2

Manoharan, L., Rosenstock, N. P., Williams, A., \& Hedlund, K. (2017). Agricultural management practices influence AMF diversity and community composition with cascading effects on plant productivity. Applied Soil Ecology, 115, 53-59. https://doi.org/10.1016/j.apsoil.2017.03.012

McGonigle, T. P., Miller, M. H., Evans, D. G., Fairchild, G. L., \& Swan, J. A. (1990). A new method which gives an objective measure of colonization of roots by vesicular-Arbuscular mycorrhizal fungi. New Phytologist, 115(3), 495-501. https://doi.org/10.1111/j.1469-8137.1990.tb00476.x

Menge, J. A., Larue, J., Labanauskas, C. K., \& Johnson, E. L. V. (1980). The effect of two mycorrhizal fungi upon growth and nutrition of avocado seedlings grown with six fertilizer treatments. J. Amer. Soc. Hort. Sci, 105(3), 400-404.

Menge, J., Davis, R., Johnson, E., \& Zentmyer, G. (1978). Mycorrhizal fungi increase growth and reduce transplant injury in avocado. Hilgardia, 32(4), 6-7. https://doi.org/10.3733/ca.v032n04p6.

Moore-Gordon, C., Cowan, A. K., \& Wolstenholme, B. N. (1997). Mulching of avocado orchards to increase Hass yield and fruit size and boost financial rewards a three-season summary of research findings. South African Avocado Growers' Association Yearbook, 20, 46-49.

Oehl, F., Laczko, E., Bogenrieder, A., Stahr, K., Bösch, R., van der Heijden, M., \& Sieverding, E. (2010). Soil type and land use intensity determine the composition of arbuscular mycorrhizal fungal communities. Soil Biology and Biochemistry, 42(5), 724-738. https://doi.org/10.1016/j.soilbio.2010.01.006

Oehl, F., Sieverding, E., Ineichen, K., Mäder, P., Boller, T., \& Wiemken, A. (2003). Impact of land use intensity on the species diversity of arbuscular mycorrhizal fungi in agroecosystems of Central Europe. Applied and Environmental Microbiology, 69(5), 2816-2824. https://doi.org/10.1128/AEM.69.5.2816-2824.2003

Oehl, F., Sieverding, E., Ineichen, K., Maeder, P., Wiemken, A., \& Boller, T. (2009). Distinct sporulation dynamics of arbuscular mycorrhizal fungal communities from different agroecosystems in long-term microcosms. Agriculture, Ecosystems \& Environment, 134(3-4), 257-268. https://doi.org/10.1016/j.agee. 2009.07.008

Pereira, C. M. R., da Silva, D. K. A., de Almeida Ferreira, A. C., Goto, B. T., \& Maia, L. C. (2014). Diversity of arbuscular mycorrhizal fungi in Atlantic forest areas under different land uses. Agriculture, Ecosystems \& Environment, 185, 245-252. https://doi.org/10.1016/j.agee.2014.01.005 
Ploetz, R. C. (2007). Diseases of tropical perennial crops: Challenging problems in diverse environments. Plant Disease, 91(6), 644-663.

Reynolds, S. G. (1970). The gravimetric method of soil moisture determination Part IA study of equipment, and methodological problems. Journal of Hydrology, 11(3), 258-273. https://doi.org/10.1016/0022-1694(70) 90066-1

Salazar-Garcia, S., \& Cortés-Flores, J. I. (1986). Root distribution of mature avocado trees growing in soils of different texture. Calif. Avocado Soc. Yrbk, 70, 165-174.

Schnoor, T. K., Lekberg, Y., Rosendahl, S., \& Olsson, P. A. (2011). Mechanical soil disturbance as a determinant of arbuscular mycorrhizal fungal communities in semi-natural grassland. Mycorrhiza, 21(3), 211-220. https://doi.org/10.1007/s00572-010-0325-3

Soti, P. G., Jayachandran, K., Koptur, S., \& Volin, J. C. (2015). Effect of soil pH on growth, nutrient uptake, and mycorrhizal colonization in exotic invasive Lygodium microphyllum. Plant Ecology, 216(7), 989-998. https://doi.org/10.1007/s11258-015-0484-6

Staddon, P. L., Ramsey, C. B., Ostle, N., Ineson, P., \& Fitter, A. H. (2003). Rapid turnover of hyphae of mycorrhizal fungi determined by AMS microanalysis of 14C. Science, 300(5622), 1138-1140. https://doi.org/10.1126/science.1084269

Storer, D. A. (1984). A simple high sample volume ashing procedure for determination of soil organic matter. Communications in Soil Science and Plant Analysis, 15(7), 759-772. https://doi.org/10.1080/0010362840 9367515

Tahat, M. M., \& Sijam, K. (2012). Mycorrhizal fungi and abiotic environmental conditions relationship. Research Journal of Environmental Sciences, 6(4), 125-133. https://doi.org/10.3923/rjees.2012

Toprak, B., Soti, P., Jovel, E., Alverado, L., \& Jayachandran, K. (2017). Mycorrhizal fungi status in organic farms of south Florida. Mycosphere, 8(7), 951-958. https://doi.org/10.5943/MYCOSPHERE/8/7/10

Urcelay, C., Diaz, S., Gurvich, D. E., Chapin III, F. S., Cuevas, E., \& Dominguez, L. S. (2009). Mycorrhizal community resilience in response to experimental plant functional type removals in a woody ecosystem. Journal of Ecology, 97(6), 1291-1301. https://doi.org/10.1111/j.1365-2745.2009.01582.x

USEPA, M. (1983). Methods for chemical analysis of water and wastes. Environmental Monitoring and Support Laboratory, Cincinnati, OH, USA.

van der Heyde, M., Ohsowski, B., Abbott, L. K., \& Hart, M. (2017). Arbuscular mycorrhizal fungus responses to disturbance are context-dependent. Mycorrhiza, 27(5), 431-440. https://doi.org/10.1007/s00572-016-0759-3

Verbruggen, E., van der Heijden, M. G., Rillig, M. C., \& Kiers, E. T. (2013). Mycorrhizal fungal establishment in agricultural soils: factors determining inoculation success. New Phytologist, 197(4), 1104-1109. https://doi.org/10.1111/j.1469-8137.2012.04348.x

Viera, W., Campaña, D., Gallardo, D., Vásquez, W., Viteri, P., \& Sotomayor, A. (2017). Native mycorrhizae for improving seedling growth in avocado nursery (Persea americana Mill.). Indian J. Sci. Technol, 10(25), 1-13. https://doi.org/10.17485/ijst/2017/v10i25/110415

Xiang, D., Verbruggen, E., Hu, Y., Veresoglou, S. D., Rillig, M. C., Zhou, W., ... Chen, B. (2014). Land use influences arbuscular mycorrhizal fungal communities in the farming-pastoral ecotone of northern China. New Phytologist, 204(4), 968-978. https://doi.org/10.1111/nph.12961

\section{Copyrights}

Copyright for this article is retained by the author(s), with first publication rights granted to the journal.

This is an open-access article distributed under the terms and conditions of the Creative Commons Attribution license (http://creativecommons.org/licenses/by/4.0/). 